\title{
YOGHURT ENRICHED WITH CONJUGATED LINOLEIC ACID USING PROBIOTIC BACTERIA BIO PRODUCTION AND ADDITION OF AVOCADO FRUIT \\ El-Abd M.M ${ }^{1}$; Wafaa. B. Elsabie ${ }^{2}$; E.M. Hamad ${ }^{3}$ and Hagar.F.Saad ${ }^{4}$ \\ 1, 3 Dairy Dept faculty of agric, Cairo university \\ 2, 4 Dairy Chemistry Dept, Animal Prod. Res. Inst. ARC
}

\begin{abstract}
This study was performed to characterize the ability of active Bifidobacteria strains and Avocado to produce conjugated linoleic acid (CLA).Using Bifidobacteria such as $B$. breve, $B$. bifidum and $B$. lactis showed an increase in CLA that convert linoleic acid (LA) to conjugated linoleic acid (CLA).

In first part set yogurt was manufactured using buffalo milk $6 \%$ fat, with adding B.breve, B.bifidum and B.lactis. Each of the prepared yoghurt assessed for chemical, microbiological and organoleptic properties when fresh and during refrigerated storage at $6 \pm 1^{\circ} \mathrm{C}$ for 14 days.

Results indicated that using probiotic bacteria (B.breve, B. bifidum and B. lactis) was effective in producing conjugated linoleic acid (CLA) in yoghurt treatments during fermentation as compared with the control yoghurt. Contents of probiotic bacteria (B.breve, B. bifidum and B. lactis) were decreased in yoghurt treatments during storage, Firmness, Synersiss and $\mathrm{pH}$ values were also decreased while T.S, Fat and acidity increased.

In second part stirred yoghurt was made using the same Bifidobacteria species and $10 \%$ or $15 \%$ avocado fruit. Each of the prepared yoghurt was assessed for chemical, microbiological and organoleptic properties when fresh and during refrigerated storage at $6 \pm 1^{\circ} \mathrm{C}$ for 14 days.

Obtained results indicated that adding avocado fruit to probiotic yoghurt highly increased CLA content in all yoghurt treatments tell the end of storage period. Also Bifidobacteria counts gradually increased during storage period.

Keywords: yoghurt, CLA, bifidobacteria bacteria, Avocado.
\end{abstract}

\section{INTRODUCTION}

Conjugated linoleic acid (CLA), refers to a group of positional and geometric isomers of octadecadienoic acid (C18: 2). conjugated double bonds (i.e., the two double bonds are separated by one single bond) in either cis (c) or trans (t) configuration are present predominantly in positions 8 and 10,9 and 11,10 and 12 , or 11 and 13 . The cis 9 - trans 11 isomer is the main isomer constituting $90 \%$ of the total CLA found in dairy and beef lipids so called rumenic acid. Linoleic acid is converted to CLA by linoleic acid isomers enzyme of rumen bacteria. For these reasons, CLA occurs naturally as a mixture of isomers in dairy foods such as milk and meats derived from ruminant animals. The most abundant isomer of CLA in nature is the cis9 trans 11 (cis9 - trans 11) isomer. Commercially available CLA is usually a mixture of cis9 - trans11and trans-10, cis-12 (t10c12) isomers with other isomers as minor components. Conjugated linoleic acid isomer mixture and c9t11 and t10c12 isomers alone have been attributed to provide several health benefits that are largely based on animal and in vitro studies. 
CLA has been shown to exert various physiological functions such as anti carcinogenic, anti diabetic, anti obesity and prevention of atherosclerosis (Arunabh Bhattacharya, 2006) and (Yanagitab, 2013).The daily intake of CLA is almost $200 \mathrm{mg}$ /day are reviewed by Marialice P.C. Silvestre, (2013) and Microwaving caused a significant decrease in CLA content in milk. The loss was up to $53 \%$ (Walter Bisig., etal 2007).

Bifidobacterium species as Bifidobacterium bifidum LMG 10645, Bifidobacterium animalis subsp lactis BB12 and Bifidobacterium breve $L M C 520$ were used for increasing CLA by microbial conversion of linoleic acid to conjugated linoleic acid and in part 2 using Bifidobacterium species as Bifidobacterium bifidum LMG 10645, Bifidobacterium animalis subsp lactis BB12 and Bifidobacterium breve LMC520 with different ratios from Avocado (Persea Americana).

Many researchers investigated the role of common lactic acid bacteria in CLA production. Several strains of food grade micro-organisms have been identified as potential producers of CLA, including strains of Bifidobacterium, Enterococcus, Lactobacillus, Lactococcus, Propionibacterium and Streptococcus. These cultures may be very important for the food industry, in particular to the dairy industry, as they can be used for the production of traditional and or novel CLA enriched foods through in situ fermentation or used to obtain CLA as a food-ingredient through a biotechnological process. Probiotic or symbiotic dairy foods with potential contents of CLA have been reported by (Rodrigues D, 2011), Silva L I., (2011) and Rodrigues D., (2012).

Avocado, or Persea American (P. americana Mill.) is a kind of evergreen fruit plants of the genus Persea family .Avocado contains a variety of essential nutrients as monounsaturated fatty acids (MUFA)-rich fruit oil with $71 \%$ MUFA, $13 \%$ polyunsaturated fatty acids (PUFA) and $16 \%$ saturated fatty acids (SFA). As the avocado fruit ripens, the saturated fat decreases and the monounsaturated fatty acids. Avocados can fit into a heart healthy dietary pattern such as the DASH diet plan USDA and HHS, 2010, Jakobsen etal, 2009, de Souza., etal, 2008 and Appel .,etal (2005).

Slater.,etal., (1975), Moreno .,etal (1980) and Lu. et al (2009) showed that the use of avocado dips and spreads as an alternative to more traditional hard, SFA rich spreads or dips can assist in lowering dietary SFA intake Cited from http://www.avocadocentral.com/nutrition/avocado-spread comparison. This study aims to increase CLA content in yogurt using some spps of Bifidobacteria and avocado fruit (Persea Americana).

\section{MATERIALS AND METHODS}

\section{Materials:}

Fresh buffalo's milk: was obtained from Dairy technology Unit, Animal, Production Research Institute, Agric. Res. Center, Ministry of Agriculture. 
Yoghurt culture: Mixed culture consisted of Lactobacillus delbrueckii sub $s p$. bulgaricus and Streptococcus salivarius sub $s p$ thermophilus was obtained from Chr. Hansen's Lab A/S Copenhagen, Denmark.

Bifidobacterium strains: Bifidobacterium bifidum $L M \quad 04$, Bifidobacterium breve LMC 017 and Bifidobacterium animalis subsp. Lactis LMG 10645 were obtained from Chr. Hansen Lab., Copenhagen Denmark. Microbiological media: Microbial media used in this study were ready made using Oxid Division. Oxoid Ltd London.

Persea Americana (Avocado) fruit: was obtained from local market Methods of analysis

Moisture content: The moisture content was determined gravimetrically according to AOAC (1990) using a Vacuum Oven, Haraeus T5042EK, Germany.

$\mathrm{pH}: \mathrm{pH}$ values of yoghurt samples were estimated using a digital $\mathrm{pH}$ meter (Jenway $3505 \mathrm{pH}$ meter).

Titratable acidity: The acidity was determined by titration following the method described by A.O.A.C. (1990).

Viscosity : Viscosity of yoghurt samples was measured using a Brookfield DV- E viscometer in $100 \mathrm{ml}$ yoghurt at $20^{\circ} \mathrm{C}$.

Fat content: Fat content was determined according to A.O.AC. (2007).

Curd tension (Firmness): Curd tension (Firmness) was measured according to chanderosek hara., etal (1975). (1959).

Syneresis: Syneresis was measured as described by lowerence

Quantification of CLA production by UV spectroscopy: Total CLA determination was carried out at a wavelength of $233 \mathrm{~nm}$ in a Perkin-Elmer spectrophotometer (Lambda650 model, Beaconsfield, UK) with scan program (190-350 nm). Measurements were obtained in triplicate from $2 \mathrm{ml}$ of the lipid extract in hexane placed into quartz cuvettes. In order to verify the suitability of this method, a standard curve was constructed for the absorbance at $233 \mathrm{~nm}$ versus CLA $(\mathrm{C} 18: 2 \mathrm{c} 9, \mathrm{t} 11)$ concentration (0-30 $\lg / \mathrm{ml})$.

Lipid extraction: Lipid isolation from culture media was carried out as a variation of the method described by Alonso, Cuesta, and Gilliland (2003). Briefly: $10 \mathrm{ml}$ of culture media were centrifuged at $7500 \mathrm{rpm}, 5 \mathrm{~min}$, and $4{ }^{\circ} \mathrm{C}$. Three $\mathrm{ml}$ from the resulting supernatant were added with $6 \mathrm{ml}$ of isopropanol and vortexed for $1 \mathrm{~min}$. Addition of hexane $(5 \mathrm{ml})$ followed which were vortex for $1 \mathrm{~min}$ and finally centrifuged at $2000 \mathrm{rpm}, 5 \mathrm{~min}$, and 4 centigrade.

Microbiological analysis: Microbiological analysis was done for $B$. bifidum, B. breve and B.lactis enumerated (Dave and Shah, 1996) using the modified MRS agar supplemented with $0.05 \%$ L. cysteine-HCL. The antibiotic mixture NPNL (Neomycin sulphate, paramonycin sulphate, Nalidixic acid and lithium chloride) as a selective agent was sterilized by filtration through 0.22 $\mu \mathrm{m}$ Millipore filter (Gellman Sci., England) then added to the medium at a rate of $50 \mathrm{ml} / \mathrm{L}$ medium just before pouring into the plates. The L. cystein$\mathrm{HCL}$ solution which sterilized by filtration $(0.05 \%$ final concentration) was 
also added using MRS-Salccin agar. The plates were incubated at $37^{\circ} \mathrm{C}$ for $48 \mathrm{hrs}$. Total bacterial count was measured as suggested by The American Public Health association APHA (1992).

Preparation of probiotic set yoghurt: Fresh buffalo's milk of $6 \%$ fat was heated to $80^{\circ} \mathrm{C}$ for $20 \mathrm{~min}$, and cooled to $42^{\circ} \mathrm{C}$. Such milk was divided into 4 equal portions. The 1st was inoculated with $3 \%$ yoghurt culture (control), the 2nd inoculated with3\% yoghurt culture and Bifidobacterium bifidum (1:1), the 3rd inoculated with with3\% yoghurt culture and Bifidobacterium breve (1:1), and the 4th inoculated with $3 \%$ yoghurt culture and Bifidobacterium lactis (1:1). The prepared probiotic set yoghurt and their control were assessed for chemical, microbiological and organoleptic properties when fresh and during refrigerated storage at $6 \pm 1{ }^{\circ} \mathrm{C}$ for 14 -day.

Preparation of probiotic stirred yoghurt fortified with Avocado: Fresh buffalo's milk of $6 \%$ fat was heated to $80^{\circ} \mathrm{C}$ for $20 \mathrm{~min}$ and cooled to $42^{\circ} \mathrm{C}$. Such milk was divided into 9 equal portions. The 1st was inoculated with $3 \%$ yoghurt culture, 2 nd inoculated with $3 \%$ yoghurt culture with $100 \mathrm{gm}$ Avocado /L milk, 3rd inoculated with3\% yoghurt culture + B.bifidum (1:1) and $100 \mathrm{gm}$ Avocado /L milk, the 4 th inoculated with with3\% yoghurt culture and Bifidobacterium breve $(1: 1)+100 \mathrm{gm}$ Avocado /L milk ,the 5th inoculated with $3 \%$ yoghurt culture and B.lactis (1:1) $100 \mathrm{gm}$ Avocado /L milk), the $6^{\text {th }}$ inoculated with $3 \%$ yoghurt culture $+150 \mathrm{gm}$ avocado, the 7th inoculated with $3 \%$ yoghurt culture and B. B.Bifidum (1:1)+ $150 \mathrm{gm}$ Avocado/L milk; the 8th inoculated with with3\% yoghurt culture + B.breve $(1: 1)$ and $+150 \mathrm{gm}$ Avocado /L milk and the 9 th inoculated with $3 \%$ yoghurt culture and $\mathrm{B}$. lactis $(1: 1)+150 \mathrm{gm}$ Avocado /L milk and stirred . The prepared probiotic yoghurt were assessed for chemical, microbiological and organoleptic properties at fresh and during refrigerated storage at $6 \pm 1{ }^{\circ} \mathrm{C}$ for 15 -day. etal. (2009)

Sensory evaluation: All samples were evaluated according to Clark

\section{RESULTS AND DISCUSSION}

1-Use of some Bifidobacteria species for Conjugated linoleic acid bio production in set yoghurt

Table 1. Effect of using different Bifidobacteria species on some properties of set yoghurt during cold storage $(6 \pm 1)$

\begin{tabular}{|c|c|c|c|c|c|c|c|c|c|c|c|c|c|c|}
\hline \multirow[b]{2}{*}{ reatments } & \multicolumn{2}{|c|}{$\%$ Fat } & \multicolumn{2}{|c|}{ \% T.S } & \multicolumn{5}{|c|}{ Acidity } & \multicolumn{5}{|c|}{$\mathrm{pH}$} \\
\hline & 0 & 14 & 0 & 14 & 0 & 3 & 7 & 10 & 14 & 0 & 3 & 7 & 10 & 14 \\
\hline & & & & & & & --(Da) & & & & & & & \\
\hline 1 & 6.00 & 6.03 & 15.2 & 16.0 & 0.63 & 0.73 & 0.82 & 0.91 & 1.00 & 4.63 & 4.54 & 4.46 & 4.33 & 4.21 \\
\hline 2 & 6.00 & 6.03 & 15.1 & 16.0 & 0.66 & 0.76 & 0.88 & 0.99 & 1.15 & 4.54 & 4.44 & 4.33 & 4.25 & 4.10 \\
\hline 3 & 6.00 & 6.03 & 15.1 & 16.3 & 0.68 & 0.80 & 0.92 & 1.08 & 1.21 & 4.57 & 4.49 & 4.34 & 4.21 & 3.94 \\
\hline 4 & 6.00 & 6.03 & 15.3 & 16.5 & 0.64 & 0.75 & 0.84 & 0.94 & 1.10 & 4.57 & 4.47 & 4.32 & 4.19 & 4.06 \\
\hline
\end{tabular}

1- Control yoghurt culture (3\%)

2- Yoghurt culture + Bifidobacterium bifidum (3 \%) 1:1.

3- Yoghurt culture + Bifidobacterium breve (3\%) 1:1.

4- Yoghurt culture + Bifidobacterium lactis (3\%) 1:1. 
Data presented in table (1) show an increase in fat and total solids (T.S) contents of yoghurt samples after 14 days of cold storage $\left(6 \pm 1^{\circ} \mathrm{C}\right)$. These increases could be attributed to water evaporation during storage period. Gradual increasing in yoghurt titratable acidity (as lactic acid \%) was also observed during cold storage period while $\mathrm{pH}$ values of the same samples showed the opposite trend.

Table 2. Conjugated linoleic acid content of set yoghurt treatments fortified with some Bifidobacteria spps during cold storage $(6 \pm 1)$

\begin{tabular}{|c|c|c|c|c|c|c|c|c|}
\hline \multirow[b]{2}{*}{ Treatments } & \multicolumn{8}{|c|}{ CLA content (mg/ $100 \mathrm{gm}$ fat) } \\
\hline & 0 & $\begin{array}{c}\% \\
\text { Increasing }\end{array}$ & 3 & $\begin{array}{c}\% \\
\text { Increasing } \\
\end{array}$ & 10 & $\begin{array}{c}\% \\
\text { Increasing }\end{array}$ & 14 & $\begin{array}{c}\% \\
\text { Increasing }\end{array}$ \\
\hline 1 & 0.18 & 0000 & $0.23 \mid$ & 0000 & 0.30 & 0000 & $0.41 \mid$ & 0000 \\
\hline 2 & 0.33 & 88.00 & 0.52 & 127.5 & 0.64 & 112.5 & 0.87 & 110.0 \\
\hline 3 & 0.37 & 109.5 & 0.48 & 112.7 & 0.75 & 148.5 & 1.02 & 147.5 \\
\hline 4 & 0.28 & 60.00 & 0.44 & 95.50 & 0.60 & 99.6 & 0.74 & 77.90 \\
\hline
\end{tabular}

Data tabulated in table 2 clearly show a noticeable increase in fresh yoghurt CLA contents when Bifidobacteria species were incorporated with yoghurt starters comparing to control treatment (1). CLA concentrations of probiotic yoghurt treatments 2,3 and 4 (containing Bifidobacterium species) were nearly the twice. On the other hand gradual increases in CLA content of all yoghurt treatments during cold storage period were observed tell 14 days. The highest CLA content was recorded in treatments (3) samples (Bifidobacterium breve) after 14 days of storage (the end of storage period). Samples of treatments (2 and 4) (Bifidobacterium bifidum and Bifidobacterium lactis) showed less CLA content than samples of treatments (3).Obtained results are in accordance with those found by Kianoush .,et al (2014).

Table 3.Changes in some rehological properties of set yoghurt treatments during cold storage $(6 \pm 1)$

\begin{tabular}{|c|c|c|c|c|c|c|c|c|}
\hline \multirow[b]{2}{*}{ Treatments } & \multicolumn{4}{|c|}{ Firmness \gm } & \multicolumn{4}{|c|}{ Synersiss $\backslash \mathrm{ml}$} \\
\hline & 0 & 3 & 10 & 14 & 0 & 3 & 10 & 14 \\
\hline 1 & 50.6 & |49.2 & 45.0 & 43.0 & ri & $r$. & 11 & 17 \\
\hline 2 & 48.6 & 46.6 & 42.0 & 39.0 & rT & rT & r) & 19 \\
\hline 3 & 45.7 & 44.0 & 39.9 & 37.8 & r & ro & rr & $r$. \\
\hline 4 & 44.6 & 42.8 & 40.0 & 36.9 & $r \varepsilon$ & ro & r & r) \\
\hline
\end{tabular}

Changes in yoghurt sample firmness and synersiss are presented in table (3). The obtained results show gradual decrease in both firmness and synersiss values tell the end of storage period. In general probiotic yoghurt samples (treatments 2, 3 and 4) showed lower firmness values and higher synersiss volumes as compared with control samples (treatment 1) during storage period. There findings are in agreement with those obtained by Ali., etal (2013) and Moayednia (2014). 
Table 4.Changes of Bifidobacteria counts in set yoghurt treatments during cold storage $(6 \pm 1)$

\begin{tabular}{|c|c|c|c|c|c|c|c|}
\hline \multirow[b]{2}{*}{ Treatments } & \multicolumn{7}{|c|}{ Changes in Bifidobacteria spps counts $\left(10^{\prime}\right)$} \\
\hline & 0 & $\begin{array}{c}\% \\
\text { Decreasing }\end{array}$ & 3 & $\begin{array}{c}\% \\
\text { Decreasing }\end{array}$ & 10 & $\begin{array}{c}\% \\
\text { Decreasing }\end{array}$ & 14 \\
\hline 1 & nd & 000 & nd & 000 & nd & 000 & nd \\
\hline 2 & 196 & 3.00 & 189 & 13.5 & 169 & 12.5 & 171 \\
\hline 3 & 168 & 8.00 & 154 & 11.0 & 148 & 14.8 & 143 \\
\hline 4 & 176 & 5.80 & 166 & 5.50 & 168 & 7.30 & 163 \\
\hline
\end{tabular}

Table 4 showed that bifidobacterium breve, bifidobacterium bifidum and bifidobacterium lactis count decreased gradually during storage period for 14 days because of increase of acidity, Low oxygen content and low redox potentials have been cited as important factors for the viability of bifidobacteria during storage of fermented milk products (Brunner .,etal 1993a and 1993b).

\section{Table 5. Sensory evaluation of fresh set yoghurt treatments}

\begin{tabular}{|l|c|c|c|c|}
\hline Treatment & Flavor(20) & Color(10) & Texture(10) & $\begin{array}{c}\text { Sensory } \\
\text { evaluation(40) }\end{array}$ \\
1 & 19 & 10 & 9 & 38 \\
2 & 18 & 10 & 8 & 36 \\
3 & 17 & 10 & 8 & 35 \\
4 & 16 & 10 & 8 & 34 \\
\hline
\end{tabular}

Sensory evaluation (total score 40) of fresh yoghurt samples are shown in table (5). Tabulated data show that control samples gained the highest score reaching 38, while probiotic yoghurt samples gained less score specially treatment (4) (with B.lactis).

$\Pi$-Enrichment of probiotic stirred yoghurt with avocado fruit

Table (6) Effect of adding avocado fruit on some properties of probiotic stirred yoghurt during cold storage $(6 \pm 1)$

\begin{tabular}{|c|c|c|c|c|c|c|c|c|c|c|c|c|c|c|}
\hline \multirow[b]{2}{*}{ reatments } & \multicolumn{2}{|c|}{$\%$ Fat } & \multicolumn{2}{|c|}{$\%$ T.S } & \multicolumn{5}{|c|}{ Acidity } & \multicolumn{5}{|c|}{$\mathrm{pH}$} \\
\hline & 0 & 14 & 0 & 14 & 0 & 3 & 7 & 10 & 14 & 0 & 3 & 7 & 10 & 14 \\
\hline 1 & 6.00 & 6.10 & 15.2 & 16.0 & 0.64 & 0.73 & 0.82 & 0.92 & 1.00 & 4.62 & & 4.46 & 4.33 & 4.21 \\
\hline 2 & 6.90 & 7.20 & 20.6 & 21.7 & 0.69 & 0.79 & 0.88 & 0.96 & 1.10 & 4.42 & 4.31 & 4.22 & 4.11 & 4.01 \\
\hline 3 & 6.90 & 7.20 & 20.6 & 21.6 & 0.71 & 0.83 & 0.90 & 1.07 & 1.21 & 4.35 & 4.21 & 4.11 & 4.00 & 3.87 \\
\hline 4 & 6.90 & 7.20 & 20.6 & 21.7 & 0.73 & 0.88 & 0.99 & 1.13 & 1.28 & 4.32 & 4.17 & 4.03 & 3.89 & 3.78 \\
\hline 5 & 6.90 & 7.10 & 20.8 & 21.9 & 0.69 & 0.82 & 0.90 & 1.00 & 1.17 & 4.37 & 4.28 & 4.10 & 3.97 & 3.86 \\
\hline 6 & 7.30 & 7.60 & 20.8 & 21.7 & 0.71 & 0.84 & 0.92 & 1.11 & 1.24 & 4.27 & 4.18 & 4.07 & 3.91 & 3.88 \\
\hline 7 & 7.30 & 7.60 & 20.9 & 21.8 & 0.73 & 0.88 & 1.00 & 1.16 & 1.32 & 4.36 & 4.29 & 4.16 & 4.02 & 3.92 \\
\hline 8 & 7.30 & 7.60 & 20.692 & 21.668 & 0.74 & 0.90 & 1.02 & 1.21 & 1.37 & 4.30 & 4.18 & 4.05 & 3.88 & 3.71 \\
\hline 9 & 7.30 & 7.70 & 20.686 & 21.635 & 0.72 & 0.88 & 0.96 & 1.14 & 1.26 & 4.34 & 4.20 & 4.10 & 3.91 & 3.81 \\
\hline
\end{tabular}

1-Control yoghurt culture (3\%).

2-Yoghurt culture $(3 \%)+100 \mathrm{gm}$ avocado/1 liter milk.

3-Yoghurt culture + bifidobacterium bifidum $(1: 1)+100$ gm avocado / 1 liter milk.

4-Yoghurt culture + bifidobacterium breve (1:1) +100 gm avocado / 1 liter milk.

5-Yoghurt culture + bifidobacterium lactis (1:1) +100 gm avocado / 1 liter milk.

6- Yoghurt culture (3\%) +150 gm avocado / 1 liter milk.

7- Yoghurt culture + bifidobacterium bifidum 1:1+ $150 \mathrm{gm}$ avocado / 1 liter milk.

8-Yoghurt culture + bifidobacterium breve (1:1) +150 gm avocado / 1 liter milk.

9- Yoghurt culture + bifidobacterium lactis (1:1) +150 gm avocado / 1 liter milk. 
Effect of adding avocado fruit (10 or $15 \%$ ) on fat, T.S, acidity and $\mathrm{pH}$ of probiotic yoghurt samples during cold storage is shown in table (6). Tabulated data showed obvious increase in fat and T.S content due to avocado addition in fresh yoghurt samples. During cold storage fat and T.S content were increased as mentioned before in table (1) due to water evaporation. Titratable acidity of yoghurt sample gradually increased through out storage period while $\mathrm{pH}$ values decreased tell the end of storage. Addition of avocado fruit clearly affected titratable acidity and $\mathrm{pH}$ of fresh yoghurt samples.

Table7.Content of CLA in stirred yoghurt fortified with some Bifidobacteria spps and different ratios of avocado during cold storage $(6 \pm 1)$

\begin{tabular}{|c|c|c|c|c|c|c|c|c|}
\hline \multirow[b]{2}{*}{ Treatments } & \multicolumn{8}{|c|}{ CLA content (mg/ $100 \mathrm{gm}$ fat) } \\
\hline & 0 & $\begin{array}{c}\% \\
\text { Increasing }\end{array}$ & 3 & $\begin{array}{c}\% \\
\text { Increasing }\end{array}$ & 10 & $\begin{array}{c}\% \\
\text { Increasing }\end{array}$ & 14 & $\begin{array}{c}\% \\
\text { Increasing }\end{array}$ \\
\hline 1 & 0.18 & 0000 & 0.28 & 000 & 0.30 & 000 & 0.41 & 000 \\
\hline 2 & 1.10 & 513.4 & 1.22 & 437 & 1.82 & 500 & 2.56 & 518 \\
\hline 3 & 1.18 & 562.9 & 1.46 & 542 & 2.40 & 691 & 2.80 & 575 \\
\hline 4 & 1.67 & 838.2 & 1.70 & 649 & 2.72 & 797 & 3.09 & 647 \\
\hline 5 & 1.04 & 485.3 & 1.20 & 430. & 1.85 & 510 & 2.31 & 458 \\
\hline 6 & 1.37 & 671.3 & 1.75 & 672.6 & 2.56 & 744 & 2.86 & 591 \\
\hline 7 & 1.57 & 783.7 & 1.99 & 777.9 & 2.83 & 834 & 3.33 & 705 \\
\hline 8 & 1.93 & 987.0 & 2.35 & 937.4 & 3.25 & 972 & 3.64 & 780 \\
\hline 9 & 1.40 & 687 & 1.80 & 691 & 2.62 & 764 & 3.10 & 650 \\
\hline
\end{tabular}

Results in table (7) indicated that CLA contents gradually increased during storage period. Also these results obviously showed significant increase in CLA content when avocado fruit was added to yoghurt samples. In other hand CLA content increasing was positively correlated with avocado concentration used. On the other hand CLA content increasing was positively correlated with avocado concentration used.

Table 8.changes in viscosity of stirred Yoghurt treatments fortified with avocado during cold storage $(6 \pm 1)$

\begin{tabular}{|c|c|c|c|c|}
\hline \multirow[b]{2}{*}{ Treatment } & \multicolumn{4}{|c|}{ Viscosity(cp) } \\
\hline & 0 & 3 & 10 & 14 \\
\hline 1 & 6000 & 6600 & 8800 & 9800 \\
\hline 2 & 9000 & 9800 & 12400 & 13200 \\
\hline 3 & 8000 & 9000 & 11700 & 12400 \\
\hline 4 & 8500 & 9300 & 11800 & 12300 \\
\hline 5 & 8700 & 9700 & 12000 & 12800 \\
\hline 6 & 10100 & 11000 & 11700 & 13700 \\
\hline 7 & 9700 & 10300 & 11400 & 12900 \\
\hline 8 & 9700 & 10800 & 11800 & 12900 \\
\hline 9 & 10000 & 11000 & 12300 & 13400 \\
\hline
\end{tabular}


In general CLA increase could be attributed to avocado addition and conversion of LA to CLA during biohydrogenation by bifidobacteria species. (Milutal, 1992). The highest CLA content was recorded in treatments (9) sample (Bifidobacterium breve $+150 \mathrm{gm}$ avocado fruit) after 14 days of storage (the end of storage period). Samples of other treatments showed less CLA content than samples of treatments (9).

Data presented in table (8) show gradual increases in viscosity values of Yoghurt treatments during storage period. Viscosity increase could be due to acidity development and avocado fortification. (Davenport,2013).

Table 9. Changes of Bifidobacteria counts in stirred yoghurt treatments fortified with avocado during cold storage $(6 \pm 1)$

\begin{tabular}{|c|c|c|c|c|c|c|c|}
\hline \multirow[b]{2}{*}{ Treatments } & \multicolumn{7}{|c|}{ Changes in Bifidobacteria spps counts $\left(10^{\prime}\right)$} \\
\hline & 0 & $\begin{array}{c}\% \\
\text { Increasing }\end{array}$ & 3 & $\begin{array}{c}\% \\
\text { Increasing }\end{array}$ & 10 & $\begin{array}{c}\% \\
\text { Increasing }\end{array}$ & 14 \\
\hline 1 & nd & & nd & & nd & & nd \\
\hline 2 & nd & & nd & & nd & & nd \\
\hline 3 & 364 & 19.7 & 436 & 35.7 & 494 & 44.0 & 525 \\
\hline 4 & 240 & 29.0 & 310 & 67.0 & 401 & 113 & 512 \\
\hline 5 & 286 & 15.7 & 331 & 51.0 & 432 & 92.3 & 550 \\
\hline 6 & nd & & nd & & nd & & nd \\
\hline 7 & 389 & 28.0 & 498 & 58.0 & 616 & 82.0 & 708 \\
\hline 8 & 261 & 38.0 & 361 & 73.0 & 452 & 120 & 575 \\
\hline 9 & 314 & 20.0 & 377 & 51.0 & 475 & 92.0 & 605 \\
\hline
\end{tabular}

Table 9 showed that Bifidobacterium breve, Bifidobacterium bifidum and Bifidobacterium lactis counts gradually increased during storage period for 14 days due to avocado addition. The highest increase of Bifidobacterium counts was recorded with Bifidobacterium bifidum treatments as it was previously mentioned (table4). Increase of probiotic bacterial counts could be ascribed by the simultaneous presence of inhibitory compounds such as antibacterial poly phenolics (Ripa.,etal ,2009).

Results in table (10) showed sensory evaluation of fresh probiotic yoghurt treatments fortified with avocado fruit. Almost no differences were recorded between all treatments except control sample (1).

Table 10. Sensory evaluation of fresh stirred yoghurt treatments fortified with avocado

\begin{tabular}{|c|c|c|c|c|}
\hline Treatments & Flavor(20) & Color(10) & Texture(10) & Sensory evaluation(40) \\
\hline 1 & 19 & 10 & 9 & 38 \\
\hline 2 & 15 & 8 & 9 & 32 \\
\hline 3 & 15 & 8 & 9 & 32 \\
\hline 4 & 15 & 8 & 9 & 32 \\
\hline 5 & 15 & 8 & 9 & 32 \\
\hline 6 & 16 & 7 & 9 & 32 \\
\hline 7 & 16 & 7 & 9 & 32 \\
\hline 8 & 15 & 7 & 9 & 31 \\
\hline 9 & 16 & 7 & 9 & 32 \\
\hline
\end{tabular}




\section{REFERENCES}

A.O.A.C. (1990). Official Methods of Analysis Chemists, 15th ed. association of Official Analytical Chemists AOAC, USA, Virginia, Arlington.

A.O.A.C. (1997). Official Method of Analysis, 15th ed. AOAC, Washington, DC, USA.

A.O.A.C. (2007). Official methods of analysis of the Association of the Analytical Chemists. 17 ED. Published by the Association of official analytical chemists. PO Box 540. Benjamin Franklin station Washington DC20044.

A.P.H.A. (American Public Health Association)(1992). Standard Methods for examination of Dairy products. American Public Health Association. Inc 16th ED Publ. Avico Inc. Westport Connecticut USA.

Ali, F. S.; Saad O. A.O and Salwa,A .G. Hussein (2013). Probiotic stability of yoghurts during refrigerated storage. Egypt. Egyptian Academic Journal of Biological Sciences 5(2): 9-19.

Alonso, L., Cuesta, E. P., \& Gilliland, S. E. (2003). Production of free conjugated linoleic acid by lactobacillus acidophilus and lactobacillus casei of human intestinal origin. Journal of Dairy Science.86: 19411946.

Appel L. J., Sacks F. M., Carey V. J., Obarzanek E., Swain J. F., Miller E. R., Conlin P. R., Erlinger B. A., Rosner B. A., Rosner B. A., Laranjo N. M., Chatleston J., McCarron P., Bishop L. M.(2005). Effect of protein, monounsaturated fat and carbohydrate intake on blood pressure and serum lipids: Results of the Omni Heart randomized trial. Journal of the American Medical Association. 294:2455-2464.

Arunabh Bhattacharya, J. B., Mizanur Rahman, Jennifer Causey, Gabriel Fernandesemail (2006). Biological effects of conjugated linoleic acids in health and disease. Journal of Nutritional Biochemistry. 17(12): 19.

Brunner JC, Spillman H, Puhan Z. (1993a). Metabolism and survival of bifidobacteria in fermented milk during cold storage. Milchwirtschaftliche 22:19-25.

Brunner JC, Spillman H, Puhan Z. (1993b). Changes in pH, free sulphydryl groups, oxygen and redox potential during fermentation of milk with Bifidobacterium longum. Milchwirtschaftliche 22: 19-25.

Candrosek hara.M.R., Bhajawan. RK. Swaminan.M. and Subrahmanyan ,V.(1975). The use of mammalian milk food processed with foods in feeding of infants. Indian journal of child health.701.

Clark,S.,Drake,M.A.,Cotello,M. and Body felt ,F.(2009).The sensory evaluation of dairy products .221-222.Springer science + Business media, LLC, New York.

Davenport.,et al. (2013). Hass Avocado Composition and Potential Health Effects. Critical Reviews in Food Science and Nutrition 53: 738-750. 
De Souza R. J., Swain J. F., Appel L. J., Sacks F. M. (2008). Alternatives for macronutrient intake and chronic disease: A comparison ofthe OmniHeart diets with popular diets and with dietary recommendations. American Journal Clinical Nutrition.88:1-11.http:// www. avocadocentral. com / nutrition / avocado-spread- comparison.

Jakobsen, M. U., O'Reilly, S., Heitmann, B. L., Pereira, M. A., Balter, K., Fraser, G. E., Goldbourt, U., Hallmans, G., Knekt, P., Liu, S., Pietinen, P., Spiegelman, D., Stevens, J., Virtamo, J. and Willett, W. C. (2009). Major types of dietary fat and risk of coronary heart disease: A pooled analysis of 11 cohort studies. Am. J. Clin. Nutr. 89:1425-1432.

Kianoush Khosravi-Darani, Fatemeh Seyed Reihani and Reza Feili (2014). Bioproduction of Conjugated Linoleic Acid in Yogurt by Probiotic Bacteria. International Journal of Biotechnology for Wellness Industries 3: $62-68$.

Lawerences,A.J.(1959). Synersiss of rennet curd. Journal of dairy technology $.14: 166$.

Lu Q.-Y., Zhang Y., Wang Y., Lee R.-P., Gao K., Byrns R., Heber D.(2009). California Hass Avocado: Profiling of carotenoids, tocopherols, fatty acids, and fat content during maturation and from different growing areas. Journal of Agricultural and Food Chemistry.57:10408-10413.

Marialice P.C. Silvestre, D. C. F. L., Mauro R. Silva3 and Viviane D.M. Silva (2013). Availability of Food Sources of Conjugated Linoleic Acid in Brazil. Pakistan Journal of Nutrition. 12(1): 08-11.

Milutal, Postal Bag Galil Hamaaravi.(1992). An Assessment of Processing Potential of Avocado Fruit. California Avocado Society Yearbook . 76: 137-144.

Moayednia, N. (2014). Quality Evaluation of New Developed Symbiotic Yogurt over the Storage at Refrigerator. Journal of Food Biosciences and Technology 4(1): 57-64.

Moreno A., Dorantes L., Galindez J., Guzman R. I. (1980). Effect of different extraction methods on fatty acids, volatile compounds, and physical and chemical properties of avocado (Persea americana Mill.) oil. Journal of Agricultural and Food Chemistry. 51:2216-2221.

Ripa, F.A., Haque, M., Nahar, L., Islam, M., (2009). Antibacterial, cytotoxic and antioxidant activity of Passiflora edulis Sims. European Journal of Scientific Research 31, 592-598.

Rodrigues D, R.-S. T. A. P., Gomes A M, Goodfellow B J and Freitas A C (2012). Lipolysis in probiotic and synbiotic cheese: the influence of probiotic bacteria, prebiotic compounds and ripening time on free fatty acid profiles. Food Chemistry 131(4)1414-1421.

Rodrigues D, R.-S. T. A. P., Pereira C I, Gomes A M, Malcata F X and Freitas A C (2011). The potential effect of FOS and inulin upon probiotic bacterium performance in curdled milk matrices Food Science and Technology. 44:100-108. 
Silva L I, R. D., Freitas A C, Gomes A M, Rocha-Santos T A P, Pereira M E and Duarte A C (2011). Optical fiber based methodology for screening the effect of probiotic bacteria on conjugated linoleic acid (CLA) in curdled milk. Food Chemistry 127(1): 222-227.

Slater G., Shankman S., Shepherd J. S., Alfin-Slater R. B. (1975).Seasonal variation in the composition of California avocados. Journal of Agricultural and Food Chemistry. 23:468-474.

USDA and HHS. (2010). Report of the Dietary Guidelines Advisory Committee $\mathrm{n}$ the Dietary Guidelines for Americans (Part B. Section 2: The Total iet. B2:11). U.S. Department of Agriculture and U.S. Department of Health nd Human Services. Washington, DC.

Walter Bisig, Pius Eberhara, Marius Collomba, Brita Rehberger (2007). Influence of processing on the fatty acid composition and the content of conjugated linoleic acid in organic and conventional dairy products - a review .INRA, EDP Sciences 87: 1-19.

Yanagitab, K. K. a. T. (2013). Review Health benefits of conjugated linoleicacid (CLA). Obesity Research \& Clinical Practice 8(6):525-532.

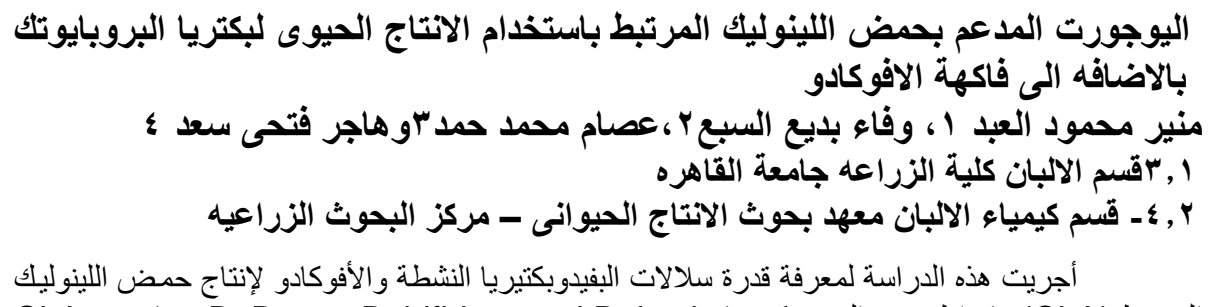

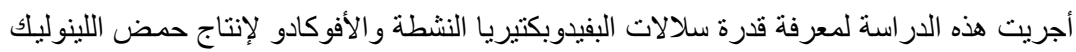

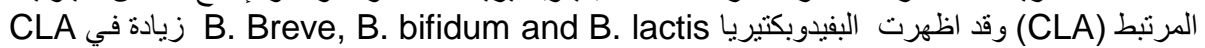

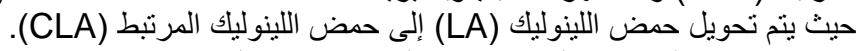

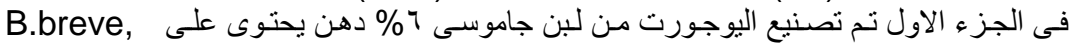

B.bifidum and B.lactis

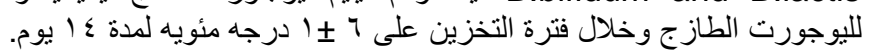

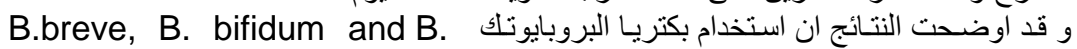
lactis

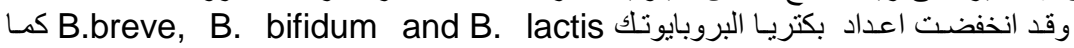

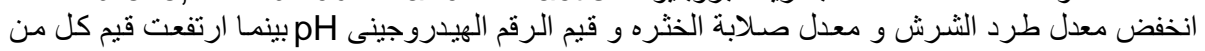

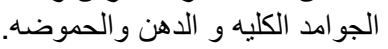

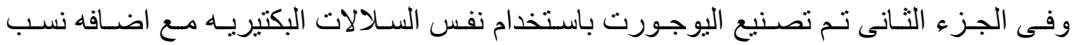

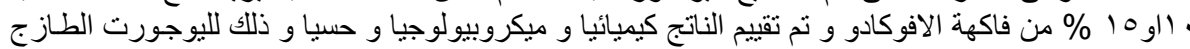

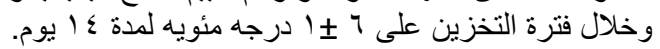

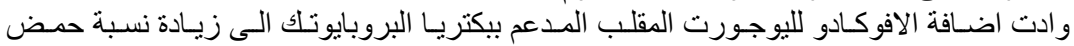

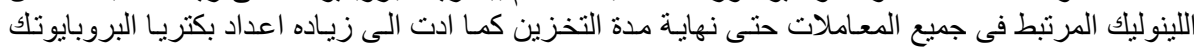

